\title{
A apropriação em El Aleph Engordado
}

\author{
Appropriation in El Aleph Engordado \\ Tatiana da Silva Capaverde \\ Universidade Federal de Roraima - Boa Vista, Roraima, Brasil
}

\begin{abstract}
Resumo: A reescrita na produção literária contemporânea tem buscado tematizar de forma metaliterária o debate sobre autoria e originalidade, não havendo melhor hipotexto que o nome de autor Jorge Luis Borges e seus textos para promover esse debate. O trabalho proposto analisa a apropriação realizada pelo autor argentino Pablo Katchadjian (1977-) do texto El Aleph de Jorge Luís Borges a fim de apontar a relação intertextual praticada e a ressignificação da autoria provocada pelas alterações propostas. A manipulação de engorde do texto e a apropriação do narrador Borges que ocorrem na narrativa El Aleph Engordado (2009) promovem questionamentos quanto aos desdobramentos autorais (Barthes), à função do autor-leitor crítico (Perrone-Moises) e à relação com a tradição (Hutcheon; Borges), permitindo a abordagem crítica sobre os deslocamentos estéticos e conceituais realizados na apropriação.
\end{abstract}

Palavras-chave: Autoria; Apropriação; Intertextualidade; Autor-leitor

\begin{abstract}
The rewriting in the contemporary literary production has been seeking to promote themes on the debate about authorship and originality in a metaliterary way, having the author's name Jorge Luis Borges and his texts as the best hypotext to promote such debate. The proposed paper analyzes the appropriation made by the Argentinian author Pablo Katchadjian (1977-) of the text El Aleph by Jorge Luís Borges, in order to indicate the intertextual relation produced and the resignification of the authorship provoked by the proposed alterations. The manipulation of the text and the appropriation of the narrator Borges which occur in the narrative El Aleph Engordado (2009) promote questions about the authorial paths (Barthes), the role of the critical author-reader (Perrone-Moises) and about the relationship with tradition (Hutcheon; Borges), allowing for a critical approach on the aesthetic and conceptual paths produced in the appropriation.
\end{abstract}

Keywords: Authorship; Appropriation; Intertextuality; Author-reader

"El Aleph", conto primeiramente publicado na revista Sur em 1945 e, posteriormente, em coletânea de mesmo nome em 1949, é um dos textos mais apropriados de Jorge Luís Borges, pois tematiza questões de autoria e originalidade, o que serve de motivação aos autores contemporâneos, que dele se apropriam, colocando textos e autores em uma dialética de continuidade e ruptura. A imagem literária da representação do universo em um único ponto já desdobrou-se por textos de diferentes autores. Pode-se afirmar que a partir da matriz textual de "El Aleph" diferentes obras foram reescritas apresentando apropriações bastante diversas em termos estílisticos, porém possuem como ponto em comum um posicionamento crítico e desconstrutor com relação aos textos borgeanos. El Aleph Engordado (2009) do argentino Pablo Katchadjian (1977) é um desses casos. $\mathrm{O}$ texto borgeano é reescrito através de um processo de inserção de vocábulos ao texto primeiro, o que faz com que o texto de Borges seja completamente preservado, no entanto, os acréscimos o ressemantizam, colocando em debate o conceito de autoria e as relações textuais no ato de apropriação do cânone.

Os deslocamentos sofridos pelos conceitos de autor e de obra permitem que a crítica lance novos olhares às produções contemporâneas e que também a literatura tematize esses deslocamentos na malha da ficção, experimentando e colocando em debate, através da forma ou da temática, questões referentes às relações 
entre autores e textos. Dessa forma, a apropriação do texto de Borges coloca em cena o autor apropriado e o autor contemporâneo e assim a autoria se faz duplamente presente, seja pela presença ausente do morto (BARTHES, 2004) ou pela vivíssima presença do autor-leitor crítico (PERRONE-MOISÉS, 1978).

A proposta intertextual de Katchadjian se caracteriza pelas relações paródicas que são, segundo Hutcheon (1989, p.13), uma das mais importantes formas da moderna auto-reflexicidadade. Trata-se da "modelação estrutural, de revisão, reexecução, inversão e 'transcontextualização' de obras de arte anterior." (1989, p.22), colocando em funcionamento uma forma de continuidade que implica um processo de transferência e reorganização do passado. $(1989$, p. 15) Também não se pode deixar de referir ao procedimento criativo de Pierre Menard de Borges. Em Pierre Menard, autor de Quijote, Borges propõe a noção de escrita como leitura a partir do princípio de que todo autor é necessariamente um leitor. Borges, através de Pierre Menard, propõe o deslocamento do texto no tempo como forma de ressignificação. Em ambas as obras, a de Borges e a de Cervantes, há a presença da leitura como forma de apropriação. Assim, como para Menard, o que está em jogo não é a originalidade da narração, mas as novas significações que um mesmo texto pode emanar. A partir destas duas noções é possível uma visada analítica da relação proposta entre textos presente em El Aleph Engordado.

É importante ressaltar que o texto de Katchadjian sofreu sanções por parte da viúva Maria Kodama, estando Katchadjian respondendo até o momento processo na justiça argentina que o acusa de plágio, o que evidencia a fratura existente entre as práticas literárias e o campo jurídico. Assim, a obra não é mais acessível de forma impressa e circula na internet via cópias digitais piratas, o que não deixa de ser significativo na medida em que propõe a não originalidade e apenas é lida através de cópias.

\section{Aleph(s)}

Aleph é a primeira letra dos alfabetos árabe, hebraico e fenício; a letra inicial do nome do Deus de Abraão (Adonai) e do Deus de Maomé (Alá). No conto de Borges, o narrador no "Pós-escrito" explica que o uso dessa nomenclatura não é casual, já que para a Cabala

(...) significa el En Soph, la ilimitada y pura divinidad; también se dijo que tiene la forma de un hombre que señala el cielo y la tierra, para indicar que el mundo inferior es el espejo y es el mapa del superior; para la Mengenlehre, es el símbolo de los números transfinitos, en los que el todo no es mayor que alguna de las partes (BORGES, 1996, p. 627).
Segundo Massuh (1980), aleph "es el universo; (...) el universo en forma instantánea y puntual. La visión del Aleph es una trascendencia desde el momento en que es superación del tiempo y del espacio: en el texto se habla de un punto que reúne lo múltiple en lo uno, y no en forma progresiva, sino simultánea." (p. 113-4) Portanto, "El Aleph" de Borges tematiza a existência de um ponto em que se projetam todas as coisas do universo: todos os tempos e espaços numa relação de infinitude.

A trama da narrativa é construída da seguinte forma: um narrador em primeira pessoa (Borges) visita periodicamente a casa de Beatriz Viterbo depois de sua morte e estabelece amizade com o primo da falecida, Carlos Argentino Daneri, poeta medíocre e pretensioso dedicado à escrita de um poema intitulado "La Tierra". Através do poema pretendia descrever o universo e confessa que o argumento do poema nasceu a partir da visão do Aleph nas dependências do porão de sua casa. $\mathrm{Na}$ iminência da demolição da casa, Daneri convida Borges para que conheça o porão. O narrador, mesmo contrariado e acreditando na loucura do poeta, aceita o convite e descreve Aleph como

(...) una pequeña esfera tornasolada, de casi intolerable fulgor. Al principio la creí giratoria; luego comprendí que ese movimiento era una ilusión producida por los vertiginosos espectáculos que encerraba. El diámetro del Aleph sería de dos o tres centímetros, pero el espacio cósmico estaba ahí, sin disminución de tamaño. Cada cosa (la luna del espejo, digamos) era infinitas cosas, porque yo claramente la veía desde todos los puntos del universo. Vi el populoso mar, vi el alba y la tarde, vi las muchedumbres de América (...), vi todas las hormigas que hay en la tierra, vi un astrolabio persa, vi en un cajón del escritorio (y la letra me hizo temblar) cartas obscenas, increíbles, precisas, que Beatriz había dirigido a Carlos Argentino, vi un adorado monumento en la Chacarita, vi la reliquia atroz de lo que deliciosamente había sido Beatriz Viterbo, vi la circulación de mi oscura sangre, vi el engranaje del amor y la modificación de la muerte, vi el Aleph, desde todos los puntos, vi en el Aleph la tierra, y en la tierra otra vez el Aleph y en el Aleph la tierra, vi mi cara y mis vísceras, vi tu cara, y sentí vértigo y lloré, porque mis ojos habían visto ese objeto secreto y conjetural, cuyo nombre usurpan los hombres, pero que ningún hombre ha mirado: el inconcebible universo (BORGES, 1996, p. 625-626).

No entanto, quando indagado por Daneri se havia visto o Aleph, nega a experiência como forma de vingança. Volta para casa preocupado pela possibilidade de não conseguir se surpreender com mais nada, mas depois percebe que o esquecimento é uma feliz solução. Nesse ponto, finaliza a narração que abarca acontecimentos desde a morte de Beatriz em 1929 à visita do porão em 
1941. Acrescenta ainda um "Pós-escrito" datado de 1943, em que informa que a casa de Daneri fora efetivamente demolida, que Daneri havia ganhado O Segundo Prêmio Nacional de Literatura com seu poema e iniciado uma carreira próspera. Levanta suspeita quanto à autenticidade de Aleph, justificadas através da citação de diferentes textos, porém relativiza as suspeitas por obra dos falseados da memória.

Permeiam em toda a narração as relações construídas tanto com Beatriz Viterbo, mulher por quem Borges fora apaixonado, quanto com Carlos Daneri, primo de Beatriz com quem estreita contato após sua morte. Entre Borges e Daneri, estabelece-se uma convivência competitiva, tendo como base o embate entre poetas e suas poéticas. Segundo Massuh (1980, p.100), "Es certo que Daneri representa una ambición poética desmesurada e por eso inútil. Además Borges se rebeló siempre contra aquellos escritores que se caracterizan por una fe compulsiva en las capacidades descriptivas del lenguaje.". Em um misto de repulsa e inveja, a relação dos dois poetas se constrói na base de muita ironia e pequenas vinganças, tendo como pano de fundo a suspeita de haverem dividido as atenções de Beatriz que, por sua vez, é uma mulher enigmática que o narrador não consegue definir. Sua imagem é apresentada a partir das descrições dos porta-retratos que estão na casa da família e pelo relato de alguns acontecimentos, muitas vezes contraditórios. A leitura feita de Beatriz pelo narrador é contraposta pelas insinuações de Daneri e pelas imagens que ele vê no porão. A revelação do Aleph mostra o caso incestuoso entre os primos e o caráter dúbio de Beatriz. Borges nutre uma relação que conjuga o amor e o ódio e busca através de informações e reconstruções da memória, após a sua morte, defini-la. No entanto, Beatriz é uma mulher de múltiplas facetas que só serão vistas em simultaneidade nas imagens promovidas pelo Aleph. Assim como Beatriz não é descritível e definível por apenas uma única imagem ou perspectiva, o universo também não o é: Aleph apresenta o mundo em sua multiplicidade e infinitude. "Esta enumeración de versiones dispares de la amada introducidas cada una por el 'Beatriz' anafórico, configura una especie de caleidoscopio múltiple que combina distintas facetas de la misma persona, pero nunca encuentra la definitiva, la buscada." (MASSUH, 1980, p. 98).

Essa multiplicidade e essa complexidade da realidade não podem ser descritas pela linguagem e, por isso, o narrador afirma:

Arribo, ahora, al inefable centro de mi relato; empieza, aquí, mi desesperación de escritor. Todo lenguaje es un alfabeto de símbolos cuyo ejercicio presupone un pasado que los interlocutores comparten; ¿cómo trasmitir a los otros el infinito Aleph, que mi temerosa memoria apenas abarca? (...) Quizá los dioses no me negarían el hallazgo de una imagen equivalente, pero este informe quedaría contaminado de Eteratura, de falsedad. Por lo demás, el problema central es irresoluble: la enumeración, siquiera parcial, de un conjunto infinito. En ese instante gigantesco, he visto millones de actos deleitables o atroces; ninguno me asombró como el hecho de que todos ocuparan el mismo punto, sin superposición y sin trasparencia. Lo que vieron mis ojos fue simultáneo: lo que transcribiré, sucesivo, porque el lenguaje lo es. Algo, sin embargo, recogeré (BORGES, 1996, p. 624).

O narrador, portanto, assume a impossibilidade da descrição da realidade. Porém, no contraste antitético dos poetas, Daneri se submete à sucessão linear da linguagem "y empreende una tarea que es la enumeración infinita de relaciones fenoménicas. Dicho con otras palabras: al someterse al lenguaje, se somete al mundo de las apariencias, porque de hecho no hay palabra capaz de describir aquello que está 'detrás' de la realidad." (MASSUH, 1980, p. 109) Em função dessa polarização presente na narrativa, pode-se dizer que "La unidad estructural que da coherencia interpretativa al relato es justamente ese elemento llamado 'Aleph'. A través de él se configuran dos actitudes literarias contrapuestas: la del narrador y la de Carlos Argentino Daneri. Dicho con otras palabras, el Aleph sería el centro a partir del cual se construyen dos poéticas diferentes." (MASSUH, 1980, p. 95)

A partir deste centro foi escrito Aleph Engordado, mais uma das imagens deste caleidoscópio que se desdobra infinitamente. A obra de Pablo Katchadjian foi lançada pela pequena editora Imprenta Argentina de Poesía, da qual o autor é editor e teve uma tiragem de 200 exemplares. Escritor que inicia sua produção com a escrita de poesia em 2004 e poesia experimental produzida a seis mãos, conjuntamente com Santiago Pintabona e Marcelo Galindo e reunida em Los Albañiles em 2005, dá continuidade a suas incursões estéticas quando publica El Martín Fierro Ordenado Alfabeticamente (2007), em que literalmente ordena o texto de José Hernández. Já em La Cadena de Desánimo (2013) realiza uma colagem de citações de declarações publicadas em jornais coletadas de 12 de março a 06 de dezembro de 2012, e o título faz alusão a uma expressão pejorativa usada pela presidente Cristina Kirchner para designar o grupo Clarín. Seu trabalho mais recente, La Libertad Total (2013), é um romance escrito em diálogos, que apresenta ausência de narrador e de referências temporais e espaciais que tornam o diálogo o centro da narração. Mais uma obra em seu histórico que busca respostas estéticas e novos formatos que contemplem novas motivações criativas. Além dos trabalhos citados que possuem uma proposta expressamente experimental e com uma recepção de 
público e crítica bastante controvertida, publicou Qué Hacer (2010), Gracias (2011) e Mucho Trabajo (2011).

Sua proposta experimental com a linguagem é apontada por César Aira em artigo (2009-2010) que analisa El Martín Fierro Ordenado Alfabeticamente e El Aleph Engordado de Katchadjian. Para Aira, os jogos com a linguagem são a forma de demonstrar a distância existente entre a comunicação e a literatura, entre a escrita e a leitura, uma vez que "la literatura es el vértice de ese torbellino linguístico, el extremo en el que todo se ordena y toma sentido. O lo pierde, en una irresponsable combinatoria lúdica, para recuperarlo como goce estético." (AIRA, 2009-2010, p. 01) A literatura está na negação dela mesma, na medida em que só assim se estabelece a dialética entre emissor e receptor. Por conjugar língua, forma e conteúdo, não possui outro instrumento que não seja sua própria estrutura: necessita inovar a partir de seu interior. Para o autor "el escritor no puede colgar el libro al revés; pero esa imposibilidad de llegar hasta el final y salir al otro lado por la puerta del formalismo lo obliga a seguir dentro de la literatura, enriqueciéndola con invenciones y maniobras, volviéndola siempre nueva, porque no hay novedad fuera de ella. (AIRA, 2009-2010, p.07) Nos textos citados, Katchadjian pratica essas manobras e invenções quando usa mecanismos combinatórios e ampliações. A diferença no procedimento empregado em El Martín Fierro Ordenado Alfabeticamente e El Aleph Engordado segundo Aira é a de que em um altera a ordem e não a extensão, no outro mantém a ordem, o enredo, mas altera a extensão. Nos dois casos, há a perspectiva da forma como diferenciador e como infinitas possibilidades, já que "El formalismo en general, ya sea radical, ya atenuado, es un juego de infinitos, al abrir la puerta a las permutaciones y las combinatorias." (AIRA, 2009-2010, p. 09)

No caso de El Aleph Engordado (2009), o texto de Borges é literalmente engordado por Katchadjian, pois são acrescentados por volta de quatro mil vocábulos ao primeiro texto. De acordo com Caballero (2012), as adições ao texto podem ser classificadas em quatro categorias: acréscimos e ampliações dos pensamentos do narrador Borges; adições de ilustrações representativas ${ }^{1}$; ampliações dos diálogos entre o narrador e Daneri e alterações das rimas dos versos do poema de Daneri; e ainda alongamento das listas impessoais de Borges, distorcendo o gesto enciclopédico com termos qualificativos. De acordo com a crítica, a vinculação do autor aos movimentos vanguardistas contextualizam o

\footnotetext{
Dado a ação judicial movida por Maria Kodama contra o autor, impedindo novas publicações do livro, não foi possível adquirir o livro publicado já esgotado. $\mathrm{O}$ trabalho foi realizado tendo como base o texto em formato pdf enviado pelo autor via e-mail. Assim, não serão considerados os paratextos e as ilustrações citadas por outros críticos nas análises.
}

procedimento em uma proposta de manipulação textual e desconstrução canônica. O conceito de apropriação parece ser produtivo para definir a proposta empregada, uma vez que rompe a lógica platônica, como afirma Perrone-Moisés (1978), e não visa reproduzir o mesmo e reverenciar a origem, mas, ao contrário, buscam produzir a diferença como semelhança simulada. Veneroso (2012) completa, apontando a liberdade criativa da apropriação:

\begin{abstract}
É assim que a arte pós-moderna, a partir da idéia do mundo como enciclopédia, se apropria, de diferentes maneiras, de idéias, imagens e objetos preexistentes como matéria-prima para seu trabalho expressivo. Essa atitude, que passou a ser conhecida como 'apropriação', nasceu da colagem, via Pop Art: 'Que cada um se autorize a si mesmo: esse é o emblema da apropriação.' (p. 72).
\end{abstract}

A maior liberdade de se realizar releituras "ilimitadas da forma e do sentido em termos de apropriação livre, sem que se vise o estabelecimento de um sentido final (coincidente ou contraditório com sentido do discurso original)" (PERRONE-MOISÉS, 1978, p.60) também é um novo caracterizador, já que reflete a noção de que a infidelidade e a apropriação são inerentes a qualquer escrita. As apropriações se apresentam de diferentes formas e estabelecem distintas relações com o passado, ampliando as relações entre textos citados até o momento.

A experiência proposta por Katchadjian é a do engorde extravagante. Através da abordagem irônica e de uso de imagens grotescas, os contrastes são apresentados. No decorrer da narrativa o narrador faz uma polarização entre ser afilado/fino e ser gordo. Através dos adjetivos empregados, pode-se observar a construção do contraste entre estar em repouso ou calmo como associado ao "estar/ser afilado"; e estar irritado ou afetado associado a estar gordo. Na passagem em que o narrador descreve as características italianas de Daneri, como gesticulação e temperamento mais colérico, essas são relacionadas a uma forma de engorde, como é possível observar na citação: "cuando se enoja se pone colorado y sus rasgos, podría decirse, engordan; curiosamente, esos rasgos engordados resultan mucho más atractivos que los finos y filosos originales." (KATCHADJIAN, 2009, p. 10-11) O narrador percebe a incongruência da relação estabelecida e procura buscar uma resposta que a explique e, então, "medio en broma, o al menos sonriendo, hojeé en mi biblioteca la primera y probablemente única edición (París, 1663) de la obra de Peruchio dedicada entre otras cosas a la fisiognomía y llegué, por azar, al dibujo correspondiente al tipo del 'extravagante' que si bien no se parecía en nada a Daneri en estado de reposo sí resultaba sorprendentemente similar al Daneri engordado." (KATCHADJIAN, 2009, p. 11). 
Percebe-se o engorde em todos os níveis narrativos, pois é através de um narrador engordado, em meio a uma narração engordada sobre um personagem engordado, que se sabe que o engorde é um ato de extravagância. A soma de vocábulos praticados pelo engorde é um artifício que provoca o estranhamento e o riso. A extravagância está presente a nível temático e linguístico. As adições feitas ao texto em sua maioria acrescentam adjetivos, ampliam questões primeiramente sugeridas ou apresentadas de forma sutil. A relação doentia entre Borges e Daneri é levada à máxima potência do sadismo, ao comportamento dúbio de Beatriz são acrescidos novos fatos, e os sentimentos torpes e mesquinhos assumem grandes dimensões através dos novos adjetivos e atos, o que significa dizer que o narrador extravasa a matéria narrada. Esse mesmo narrador, no entanto, critica esse comportamento mais expansivo e a literatura por ele classificada de ostentação verbal. Descreve Daneri de forma pejorativa, apontando seus traços italianos, seu sotaque "ceceado", sua literatura e sua forma de ser extravagante. No entanto, essa espontaneidade lhe causava inveja, como ele relata:

\begin{abstract}
Sentí que Daneri estaba perdiendo la estabilidad emocional. Eso lo hacía más interesante, y noté que incluso me daba algo de envidia: yo era incapaz de perderla; los poetas la perdían. Entendí que en eso consistía su espontaneidad: era capaz de hacer cualquier cosa que quisiera. Yo, por el contrario, seguía asociando la idea de espontaneidad a cierta reminiscencia coloquial en la sintaxis o a una pureza emocional no artificiosa en la elección léxica, pura retórica estandarizada de lo espontáneo. Era una estupidez: la verdadera espontaneidad consistía en armar una retórica propia de la espontaneidad sin pensar en los otros. Su depravado principio de ostentación verbal era espontáneo; mis correcciones y observaciones, amaneradas y pretenciosas. De todos modos, yo no era un practicante de la espontaneidad, y no estaba seguro de querer serlo (KATCHADJIAN, 2009, p. 23-24, sublinhado nosso) ${ }^{2}$
\end{abstract}

Essa relação de competição e inveja poética fica explicitada no "Posdata", quando Borges relata o prêmio recebido por Daneri: "increíblemente, mi obra Los naipes del tahur no logró un solo voto. ¡Una vez más, triunfaron la incomprensión y la envidia! Hace ya mucho tiempo que no consigo ver a Daneri; los diarios dicen que pronto nos dará otro volumen." (KATCHADJIAN, 2009, p.47). A "Posdata" não sofreu qualquer alteração por Katchadjian, mas o trecho citado acima em que Borges relata uma sensação de não ser poeta em função de não

\footnotetext{
2 Nas citações do texto de Katchadjian os acréscimos ao texto borgeanos são sublinhados para melhor entendimento da análise comparativa.
}

ser espontâneo é composto apenas por acréscimos. Pode-se concluir que o Borges de Katchadjian é mais inseguro com relação a sua escrita que o Borges de Borges, pois mesmo sofrendo incompreensões não questiona sua poética, mas, ao contrário, atribui unicamente à crítica e aos valores que regem o mercado, a causa de seu fracasso. Caballero (2012) afirma que o Borges de Katchadjian é mais auto-reflexivo, possui mais dúvida, o que inverte a posição dos personagens, já que em Borges o narrador assume uma posição de mais liderança e de segurança em termos estéticos. Esse fato é importante, pois as alterações feitas na caracterização do narrador Borges provocam um grande estranhamento, já que, além de personificar o ponto de vista da narrativa de forma engordada, uma vez que se apresenta em primeira pessoa, difere da voz conhecida de Borges que representa não só um nome como um adjetivo.

Esse estranhamento não é gratuito, pois com esse recurso o leitor é deslocado dos parâmetros estéticos e morais da escrita borgeana e é recepcionado por outra voz que introduz na narrativa a banalidade narrativa, a sexualidade escrachada e os excessos tagarelas indizíveis na voz de Borges. Como bem observa Caballero (2012), os acréscimos feitos ao texto de Borges deixam entrever uma crítica à posição conservadora de Borges tanto no que diz respeito ao estilo, que o narrador expressa através do minimalismo e do requinte lexical, quanto às posições moral e política. Além disso, Caballero (2012) ainda destaca que o ato de tornar extravagante e barroca a voz dos personagens os aproxima, desestabilizando a relação hierárquica que colocava o narrador em posição dominante além de deslocar a criação literária da utópica posição assexuada e erudita que representa o nome Borges.

Como se percebe, as alterações pouco interferem na trama propriamente, no entanto determinam mudanças significativas na caracterização dos personagens e na relação construída entre eles. Como afirma Alemian (2010) "es cierto que lo que más se destaca en una primera lectura "espontánea" de El Aleph Engordado es una cierta neurotización del narrador borgeano." (s/p) $\mathrm{Na}$ observação dos acréscimos sublinhados abaixo é possível observar essa mudança de identidade do Borges narrador:

(...) el hecho me dolió, pues comprendí que el incesante y vasto universo ya se apartaba de ella, Beatriz, y que ese cambio era el primero de una serie infinita de cambios que acabarían por destruirme también a mí. Tenía ya, un poco debido al calor y otro poco a $\underline{\text { mi nerviosismo, el cuello de la camisa completamente }}$ húmedo; me saqué la corbata y, como ofreciéndole el gesto al fantasma de Beatriz, la tiré a la basura; inmediatamente me arrepentí y estuve a punto de meter la mano en el cesto para rescatarla. "Cambiará 
el universo infinito pero yo no", pensé con melancólica vanidad autoindulgente, una vanidad autoindulgente que también me generaba una vergüenza doble cuando la descubría responsable de actos como el que acababa de realizar. Alguna vez, lo sé, mi vana devoción la había exasperado a Beatriz hasta el punto del vituperio; muerta, yo podía consagrarme a su memoria, sin esperanza pero también sin humillación. Los insultos y burlas que tanto me habían dolido desaparecían con ella; justamente, la corbata preferida de Beatriz era ahora el símbolo del comienzo de su segunda muerte. La interpretación me animó, aunque sólo se trataba de un paliativo para no sufrir la pérdida de una corbata tan fina (KATCHADJIAN, 2009, p. 7-8, sublinhado nosso).

A extravagância do narrador e seus excessos de adjetivos confrontam com um comportamento esperado de Borges. Sua atitude nervosa e insegura e sua narração que expõe situações antes apenas sugeridas trazem ao texto uma nova leitura. Uma vez que um narrador em primeira pessoa chamado Borges é relacionado diretamente ao escritor Borges através do artifício narrativo e, quando esse mesmo narrador não mais deixa entrever uma fala borgeana, o que o leitor sente é uma vertigem autoral, já que não consegue identificar a voz que fala. Essa desordem faz o leitor buscar, não a imagem da Beatriz, como faz o narrador de Borges que envolve o leitor em sua busca e ponto de vista, mas a imagem do próprio narrador que perde suas feições afiladas e ganha um engorde, isto é, uma nova versão.

A diferença entre os narradores aparece claramente nas alterações. Um exemplo bastante interessante são os acréscimos à lista que descreve o que é visto através do Aleph. A lista é bastante ampliada, e os acréscimos visam deslocar as cenas descritas da imagem poética para o detalhe realista, localista e cético.

Lo que vieron mis ojos fue simultáneo: lo que transcribiré, sucesivo, porque el lenguaje lo es. Algo, sin embargo, recogeré: no quiero ser acusado de egoísta. Y aunque lo más sincero e inteligente sería optar por el silencio, accedo porque, aun así, sigue siendo mejor escribir.

En la parte inferior del escalón, hacia la derecha, vi una pequeña esfera, y entonces pensé: "Esto es simplemente una esfera tornasolada, aunque de casi intolerable fulgor, como una bola de espejos fundida en plomo". Luego me distraje, un poco decepcionado, hasta que un fulgor mayor, violáceo, como un estallido detenido en el tiempo, me hizo volver a la esfera. Atrapado por la luz como un insecto, comencé a mirarla con fijeza hasta que ésta empezó a moverse sin salir de su lugar. (...) Así, cada cosa (la luna del espejo, digamos, por ejemplo) era infinitas cosas, porque yo claramente la veía desde todos los puntos del universo, y como los puntos de vista son infinitos, cada objeto de los infinitos objetos del universo era en sí mismo infinito. A la vez, cada objeto está conformado por infinitos puntos... Y cada uno de los puntos es infinito en sí mismo... Eso, insisto, no se puede describir. Pero como toda descripción recorta sobre lo infinito un capricho, la lista siguiente es lo que la literatura me permite en este momento, por lo demás histórico. Así que vi el populoso mar con sus barcos hundidos, vi el alba y la tarde en Budapest, vi un serrucho, vi las muchedumbres indígenas de América sometidas a la explotación y el hambre, vi una plateada telaraña en el centro de una negra pirámide que no pude identificar, vi un laberinto roto a martillazos (supe que era Londres), vi interminables ojos inmediatos escrutándose en mí como en un espejo deformante y multiplicador, vi en un pozo los restos de la corbata favorita de Beatriz rodeados de miles de bolsas de basura negras, vi todos los espejos del planeta y ninguno me reflejó porque yo no estaba delante sino en un sótano sucio (...) (KATCHADJIAN, 2009, p. 40-41, sublinhado nosso).

O trecho aponta a leitura de um outro Borges narrador que atribui diferentes valores às cenas vistas, com um propósito muito explícito de desconstrução da estética e das imagens borgeanas. Para Caballero (2012, p.6), a nova lista de Katchadjian apresenta o que Borges tem meticulosamente removido de sua escrita: história colonial, a luta de classes, o genocídio, a violência, a exploração, o caos, e todo o negócio sujo de seres humanos.

É importante salientar que a questão autoral na reescrita de El Aleph possui dois complicadores, uma vez que o relato é em primeira pessoa, e esse narrador se chama Borges, além de possuir na trama um duplo antitético, o poeta Daneri, que apresenta alguns dados biográficos de Borges, como o fato de ser poeta, argentino e bibliotecário. Daneri, segundo Massuh (1980, p. 100101), "es ante todo un anti-Borges. La actitud del primo de Beatriz frente a la poesía es justamente la antítesis de aquello que podría ser una poética de Borges. (...) A pesar de esa oposición, Carlos Argentino no deja de tener ciertos rasgos biográficos del autor." A oposição poética se observa na descrição feita por Borges da obra de Daneri que aponta a ostentação verbal e a escrita como forma de descrição total: "había elaborado un poema que parecía dilatar hasta lo infinito las posibilidades de la cacofonía y del caos," (BORGES, 1996, p.622) Por isso, a duplicação autoral já está posta a nível narrativo na medida em que o personagem-narrador é homônimo ao escritor e o personagem Daneri funciona como um duplo de Borges, com quem constrói uma relação de inveja e admiração, amor e ódio. Pode-se afirmar que o conto de Borges, em termos autorais, apresenta a duplicação da figura de Borges que, ficcionalizado e dividido, funciona como forma de mostrar as funções caleidoscópicas que coexistem em simultaneidade no autor. 
Porém, quando essa mesma narração passa a ser escrita por Katchadjian que não assume a função de narrador, a voz de Borges é falsificada e sua ficcionalização reafirmada. O Borges narrador criado por Katchadjian (assim como Daneri e a obra como um todo) também é engordado, dizendo e pensando coisas que não dizia antes. Quando o narrador Borges é engordado e passa também ao estado extravagante, sua narrativa se aproxima da de Daneri e dessa forma a construção antitética e complementar perde espaço na nova narrativa. Como esse é um dos principais fios condutores do conto, sua leitura se torna vertiginosa, pois o narrador, agora despersonalizado e afastado de sua identidade nominal, não é reconhecido e não possui um duplo complementar. O engorde, nesse caso, desloca o debate da autoria do âmbito narrativo, contrastando não mais os personagens da narração, mas sim os próprios escritores e seus procedimentos de apropriação textual. Não mais Borges e Daneri, agora Borges e Katchadjian.

Katchadjian na "Posdata" faz questão de registrar que seu procedimento possui como proposta estética o esfumaçamento entre os limites autorais e a copresença das duas vozes como jogo narrativo, quando afirma que "Con respecto a mi escritura, si bien no intenté ocultarme en el estilo de Borges tampoco escribí con la idea de hacerme demasiado visible: los mejores momentos, me parece, son esos en los que no se puede saber con certeza qué es de quién." (KATCHADJIAN, 2009, p. 50) Nesse sentido, o resultado, como afirma Mora (2011), "es a la vez respetuoso en lo textual y agresor en lo conceptual: el texto de Borges está presente, pero es radicalmente alterado por la intervención de Katchadjian, en un claro proceso distorsionador del sentido. Presencia y retorsión. Sobrevivencia y alteración de la memoria." (p.266) Na fusão proposta, a identidade da voz autoral de Katchadjian se apresenta muito mais na posição desconstrutora da voz de Borges que é despersonalizada via narrador que propriamente na construção de uma segunda voz a partir de Borges. Realiza sua crítica usando Borges como locutor. Os acréscimos visam muitas vezes à ridicularização do texto primeiro, sempre marcando a posição crítica do autor frente à estética de Borges, mas não supera o experimento a ponto de se apropriar efetivamente do texto a fim de fazê-lo outro, com nova arquitetura textual e identidade autoral.

Katchadjian constrói assim uma relação intertextual de apropriação paródica (Hutcheon, 1989), pretendendo se diferenciar em uma nova significação, ironizando a estética defendida pelo narrador Borges e estabelecendo uma relação mais horizontal entre os personagens. O texto de Katchadjian possui como proposta a desconstrução e a extrema crítica com relação à biblioteca canônica e, em função de suas vinculações com a estética das vanguardas, a desconstrução da figura do autor é algo latente, o que, em certa medida, impede que o segundo autor se coloque para além do lugar da contestação. A vanguarda estando hoje na condição de movimento histórico aponta para a impossibilidade de ruptura pelos mesmos procedimentos reutilizados pelas neovanguardas, pois estando a negação da arte transformada em uma estética artística, inviabiliza qualquer efeito de choque ou ruptura. Deve-se considerar que o uso da manipulação textual como forma de choque de sentido é um recurso datado que só representou ruptura e crítica no contexto do início do século. A reedição dos pressupostos de vanguarda não mais promove a desconstrução, ao contrário, apenas legitima atos de contestação em uma relação histórica. Atacar os textos borgeanos através da extravagância, como afirma Alemian $(2010, \mathrm{~s} / \mathrm{p})$, contraditoriamente, acaba por estabelecer uma relação com o insignificante, pois "Si intenta no diferenciarse: no agrega nada. Si la diferencia viene por el lado de la extravagancia: lo que agrega es insignificante, es como un fuego de artificio, un gag."

Através de uma manipulação explicitamente textual, o debate sobre autoria e originalidade é apropriado, a função autoral ressemantizada em novos formatos e as marcas autorais são reforçadas pelo autor contemporâneo, mesmo quando propõe a negação da autoria. Katchadjian constrói uma relação no campo da manipulação textual e marca sua presença no texto quando defende seu projeto de apropriação e com ele uma determinada forma de relação com o passado e a memória literária. Estabelece assim uma autoria crítica com o texto apropriado. Segue uma linha conceitual e de experimentação estética, produzindo um resultado neovanguardista agressivo, uma vez que corrompe o texto e a figura de Borges quando altera a voz do narrador Borges.

A apropriação do sentido metafísico do aleph e do posicionamento erudito representado pelo narrador Borges são combatidos pelo autor contemporâneo. A crítica mordaz desloca o texto borgeano do lugar da narrativa filosófica e erudita e o coloca no espaço da escrita da vida mundana. A autoria e a originalidade são praticados pelo autor que assume a função de autor-leitor crítico que desloca temporal e espacialmente um texto de seu universo de sentido e de seu lugar no cânone a fim de colocá-lo em questionamento.

Nessa perspectiva, observa-se que a noção de tradição é questionada ou perde o peso da influência como relação hierárquica entre obras e autores. No entanto, contraditoriamente, o texto canônico existe e é reconhecido, sendo chamado ao presente a fim de fazer conviver obras e autores em diferentes espaços e tempos. Não se trata da manutenção de uma continuidade ou 
origem, mas sim uma repetição que produz Outro, do surgimento do outro na reiteração. Assim, repetir ou reescrever não segue a lógica da cópia de um modelo, trata-se antes de uma autoconsciente manipulação de códigos, gêneros ou modos narrativos que rompe com qualquer continuidade pacificadora. A partir desse contexto, o que se esperava encontrar é o que Souza (2011) afirma em seu texto:

Nas lições de Borges para a literatura do presente contaminada pela metaficção, pelo convívio estreito entre documento e ficção, teoria e ficção, verdades e mentiras, bartlebys e companhias - o que se propõe é a prática da irreverência diante de sua obra, da mesma forma que ele assim entendia a leitura da tradição. $\mathrm{O}$ mimetismo e a subserviência aos modelos não constroem boa literatura, pois a leitura dos clássicos e das tradições exige rupturas e clama por um diálogo impertinente com os precursores (p. 99).

Acredita-se que é dessa busca por novas relações com o passado que nasceu a obra aqui analisada, que, além de colocar em evidência a apropriação do texto alheio, debate a ressemantização da autoria em um texto que faz conviver mais de um autor. O resultado frutífero das aproximações e rupturas presentes na apropriação é o fato de dois autores coabitarem a mesma obra, defendendo seus posicionamentos estéticos e transitando pela biblioteca com irreverência, reescrevendo seu passado, não deixando de defender seus princípios estéticos e marcando sua voz autoral. Como bem lembra Crespo (2012), "Para salir de Borges hay que parodiarlo. Hay que homenajearlo y burlarlo simultáneamente, para recordarlo y relativizarlo en un mismo gesto." (p. 56).

\section{Referências}

AIRA, César. El Tiempo y el Lugar de la Literatura. Revista de Artes y Letras, n. 19, p. 1-12, verano 2009-2010.
ALEMIAN, Ezequiel. Nota sobre El Aleph Engordado, de Pablo Katchadjian. Blog EzequielAlemian [Nota de imprensa]. 2010. Disponível em: <http://ezequielalemian.blogspot.com. br/2010/06/nota-sobre-el-aleph-engordado-de-pablo.html>. Acesso em: 15 jun. 2014.

BARTHES, Roland. A Morte do Autor. In: BARTHES, Roland. O rumor da língua. São Paulo: Martins Fontes, 2004.

BORGES, Jorge Luis. Obras completas (1923-1949). Buenos Aires: Emece, 1996. v. 1.

BORGES, Jorge Luis. Ficciones. 15.ed. Madrid: Alianza Editorial, 2009.

CABALLERO, Juan. The borgesian monad contaminated and Buenos Aires photobombed: Pablo Katchadjian's el Aleph engordado and Pola Oloixarac's Las Teorías Salvajes. Lucero, v. 1, n. 22, 2012.

CRESPO, Natalia. Parodias al Canon: reescrituras en la Literatura Hispánica Contemporánea (1975-2000). Buenos Aires: Corregidor, 2012.

HUTCHEON, Linda. Uma teoria da paródia. Lisboa: Edições 70, 1989.

KATCHADJIAN, Pablo. El Aleph engordado. Buenos Aires: IAP, 2009.

MASSUH, Gabriela. Borges: una estética del silencio. Buenos Aires: Editorial de Belgrano, 1980.

MORA, Vicente Luis. El MetaRemake: relecturas transatlánticas y transmedia de Borges. Boletín Hispánico Helvético, n. $17-18$, p. 259-278, 2011.

PERRONE-MOISÉS, Layla. Texto, escrita, escritura. São Paulo: Ática, 1978.

SOUZA, Eneida Maria. A Memória de Borges. In: SOUZA, E. M. Janelas indiscretas: ensaios de crítica biográfica. Belo Horizonte: Ed.UFMG, 2011.

VENEROSO, Maria do Carmo de Freitas. Caligrafias e escrituras: diálogos e intertexto no processo escritural nas artes no século XX. Belo Horizonte: C/Arte, 2012.

Recebido: 17 de abril de 2017

Aprovado: 26 de setembro de 2017

Contato:

Tatiana da Silva Capaverde <taticapa@ufrgs.br> 